\title{
Omega Point: An Electronic Visualisation of a Quantum Theory of Consciousness
}

\author{
Marios Athanasiou \\ Flat 4A, 1 Bramshaw Road, E9 7SN \\ London, UK \\ info@mariosathanasiou.com
}

\section{ABSTRACT}

This presentation explores Omega Point, a digital interactive art installation that works as an electronic visualisation of a new theory of consciousness as a quantum physics phenomenon.

Recent discoveries in neuroscience support a twenty-year-old controversial theory of consciousness entitled Orch-OR that states that consciousness does not emerge from complex computational activities inside the brain, as it was previously thought, but rather it emanates from quantum vibrations inside the microtubules. These microtubules are microscopic tubular structures present inside brain neurons.

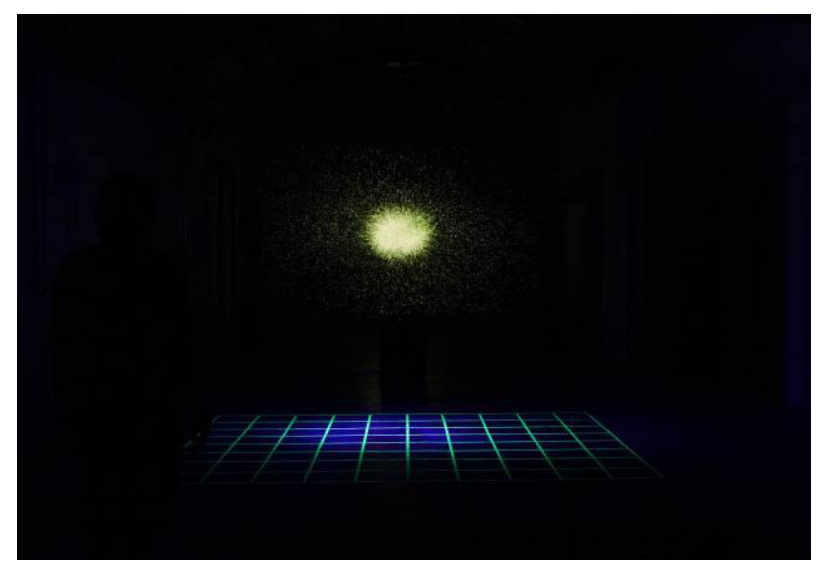

Figure 1: Proto-consciousness

According to this theory, developed by Sir Roger Penrose and Stuart Hameroff, consciousness exists as quantum information everywhere in the universe; we are merely the receivers of it rather than the creators. The title of the work is borrowed from a term first coined by the French Jesuit Pierre Teilhard de Chardin who believed that Omega Point "is the purported maximum level of complexity and consciousness towards which some believe the universe is evolving". The title Omega Point is used here to suggest that, based on the theory by Sir Roger Penrose and Stuart Hameroff, consciousness has already reached that level of maximum complexity and already exists as a force that encompasses the universe.

The electronic visualisation is achieved with the use of custom software and Kinect sensors. The work is split into two parts, the proto-consciousness and the human consciousness. In the protoconsciousness a steady harmonic drone sound is combined with the steady movement of particles in and out of a main particle-light source. It is the proto-consciousness as a Quantum Unity (Figure 1).

In the second part the participant steps into the cyber green grid and launches the Omega Point where the proto-consciousness morphs into a singular human consciousness. The sound is a non-harmonious, high-pitched noise and the participant can experience a figure of him/herself made out of the same particles as the Quantum Unity (Figure 2).

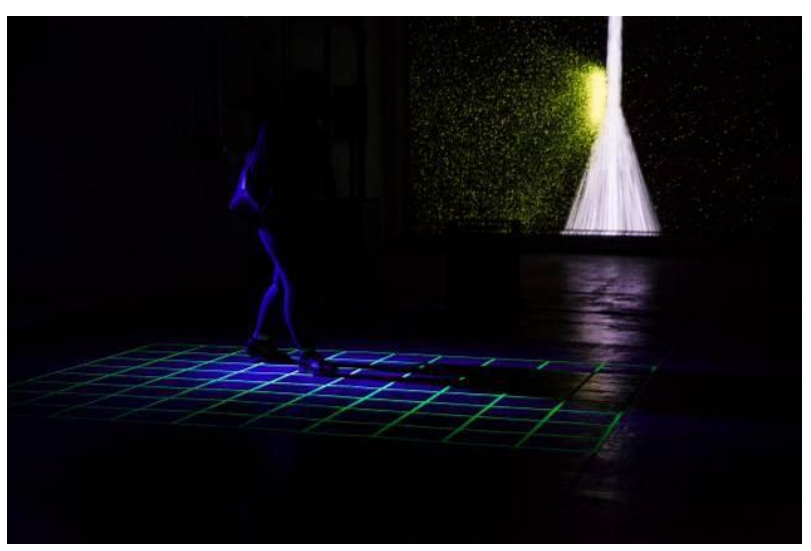

Figure 2: Human consciousness 
The installation loops between the Quantum Consciousness and Human Consciousness and it invites the participants to perceive themselves as part of a cybernetic universe of infinite quantum information feedback loops.

\section{REFERENCES}

Ascott, R. A. (ed.) (1999) Reframing Consciousness: Art, mind and technology. Intellect Books, UK.
Hameroff, S. \& Penrose, R. (2013) Consciousness in the Universe: A review of the 'Orch OR' theory. http://www.sciencedirect.com/science/article/pii/S1

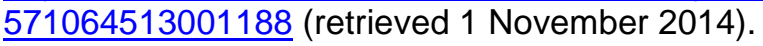

Hameroff, S. (2013) Interviewed by Nikola Danaylov on Singularity 1 on 1,12 September. http://www.youtube.com/watch?v=YpUVot-4GPM (retrieved 1 August 2014).

Tuszynski, J. A. (ed.) (2006) The Emerging Physics of Consciousness. Springer, Germany. 